\title{
Economic Growth and Population Ageing in Nigeria: Innovation Accounting Techniques
}

\author{
Ademola Obafemi Young ${ }^{1}$ \\ ${ }^{1}$ Department of Economics, Mountain Top University, Ogun State, Nigeria \\ Correspondence: Ademola Obafemi Young, Department of Economics, Mountain Top University, Ogun State, \\ Nigeria. Tel: 234-806-982-0390. E-mail: aoyoung@mtu.edu.ng
}

Received: May 30, 2018

doi:10.5539/jsd.v11n4p190
Accepted: June 16, $2018 \quad$ Online Published: July 29, 2018

URL: https://doi.org/10.5539/jsd.v11n4p190

\begin{abstract}
While global ageing suggests a triumph of social, economic, and medical advances over diseases, however, in economics regarding the growth implications of ageing, it is a puzzle as to what direction the effect will go. This motivates the current study to investigate empirically the economic growth consequences of population ageing in the context of Nigerian economy spanning between the period 1970 and 2015. Innovation Accounting Techniques was applied to assess the dynamic interactions among the variables. The results obtained revealed that the innovation in life expectancy and change in adult age dependency had the least contribution to the variation in per capita real GDP growth rate. The magnitude ranges between 1.45 and 8.33 percent. These results, thus, lend credence to the pessimistic view which contend that the inequality in a country's population age structure, particularly, a greater share of the population of the elderly, depresses the country's productivity level. Hence, the study recommends that any long term growth strategy aimed at boosting per capita income at a sustainable rate over the next ten (10) to fifteen (15) years needs to envision policies and reforms that are likely to foster savings and boost returns on them.
\end{abstract}

Keywords: population ageing, economic growth, innovation accounting techniques

\section{Introduction}

Nearly all countries in the world is experiencing growth in the number and share of the population of the elderly defined as persons aged 60 years and above, occasioned by a decline in fertility rate and rise in longevity. As of 2015, for instance, globally, this subset of population was estimated at 901 million; an upsurge of forty-eighth (48) percent over the 607 million older persons worldwide in 2000 (United Nations World Population Prospects, 2017). Presently, premised on the details published by the United Nations, Department of Economic and Social Affairs (DESA) Population Division (2017), it stands at 1 billion. Compared to 2015, it is projected to grow from 901 million to 1.4 billion in 2030, reaching 2.1 billion by 2050, more than double its size in 2015 and nearly 3.1 billion by 2100 , more than triple its size in 2015 . Though, at first experienced by advanced countries, it is now a global phenomenon experienced in almost all countries of the world (Joubert and Bradshawb, 2006).

In Europe, twenty-five (25) percent of the entire population is at present aged 60 years and above. It is projected to reach thirty-five (35) percent by 2050; and besides remain around that level in the second half of the century (World Health Organization, 2015). Conversely, in other regions, over the next several decades and continuing through 2100, population is also expected to age significantly. Africa, for instance, which currently has the youngest age population than any region, is projected to experience rapid ageing (United Nations World Population Prospects, 2017). The African population though will remain relatively young for many more decades, nonetheless, the proportion of its population aged 60 years and above is projected to increase from five (5) percent in 2017 to around nine (9) percent by 2050, and then to nearly twenty (20) percent by the end of the century.

While global ageing suggests a triumph of social, economic, and medical advances over diseases, however, in economics regarding the growth implications of ageing, it is a puzzle as to what direction the effect will go (see figures 1 and 2). The pessimistic theory contends that the inequality in a country's population age structure, particularly, a greater expanse in the old age group, depresses the country's productivity level. Put differently, the theory asserts that, other than the sharp reduction in labour force and national saving rates which in turn would lessen investment and real output; in an ageing society, fiscal problems which have profound consequences on 
economic growth, are likely to emerge. A rising old-age dependency ratio will not only translate into growing tax burden, but also, health care and public pension expenditures which will crowd out public investment spending for infrastructure with negative effects for capital accumulation and productivity growth (Gonzalez-Eiras and Niepelt, 2012; Bairoliya, Miller and Saxena, 2017).

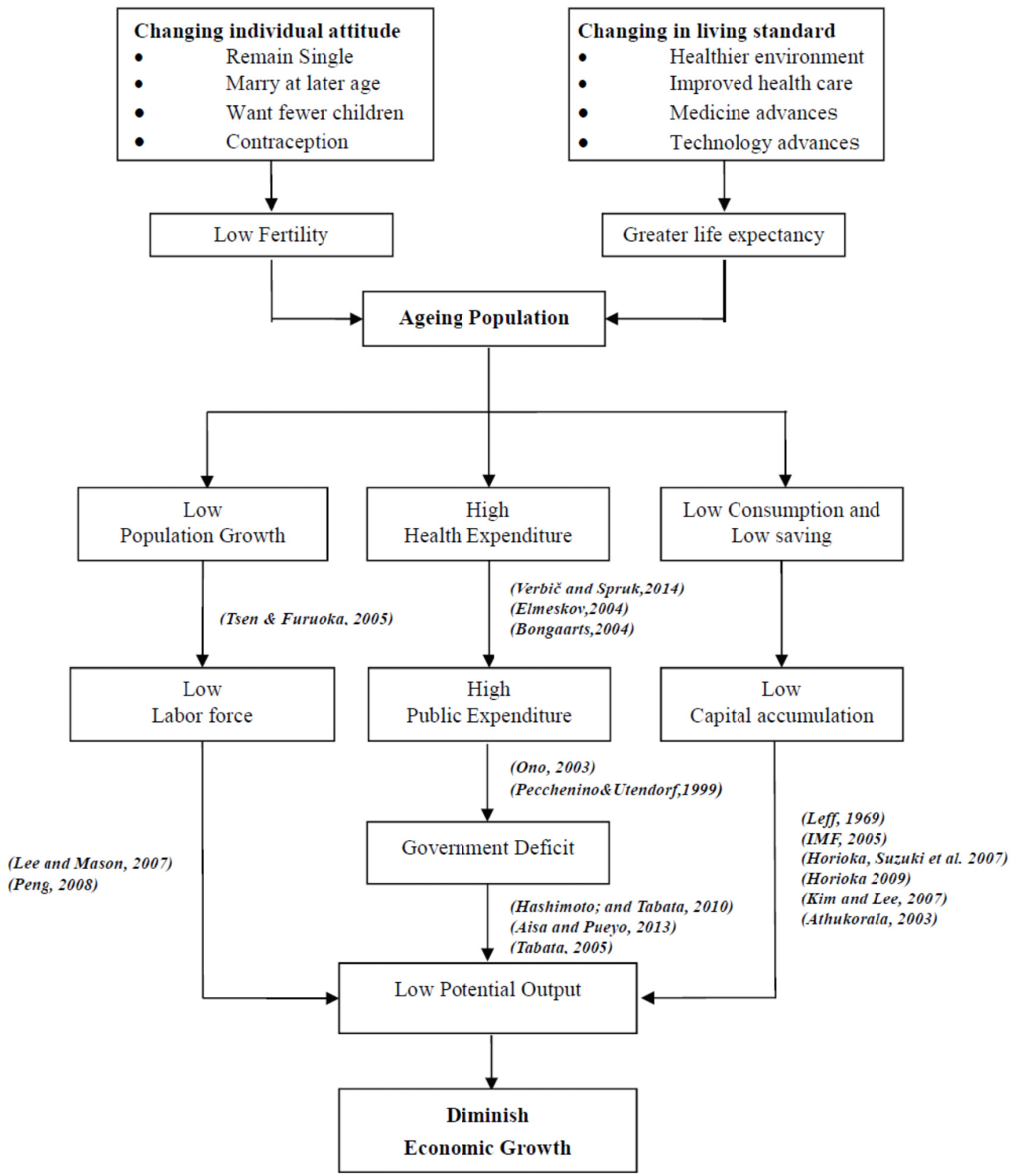

Figure 1. The pessimists view of the impact of population ageing on economic growth Source: Adapted from Sukpaiboonwat, Plyngam, and Jaroensathapornkul (2014) 


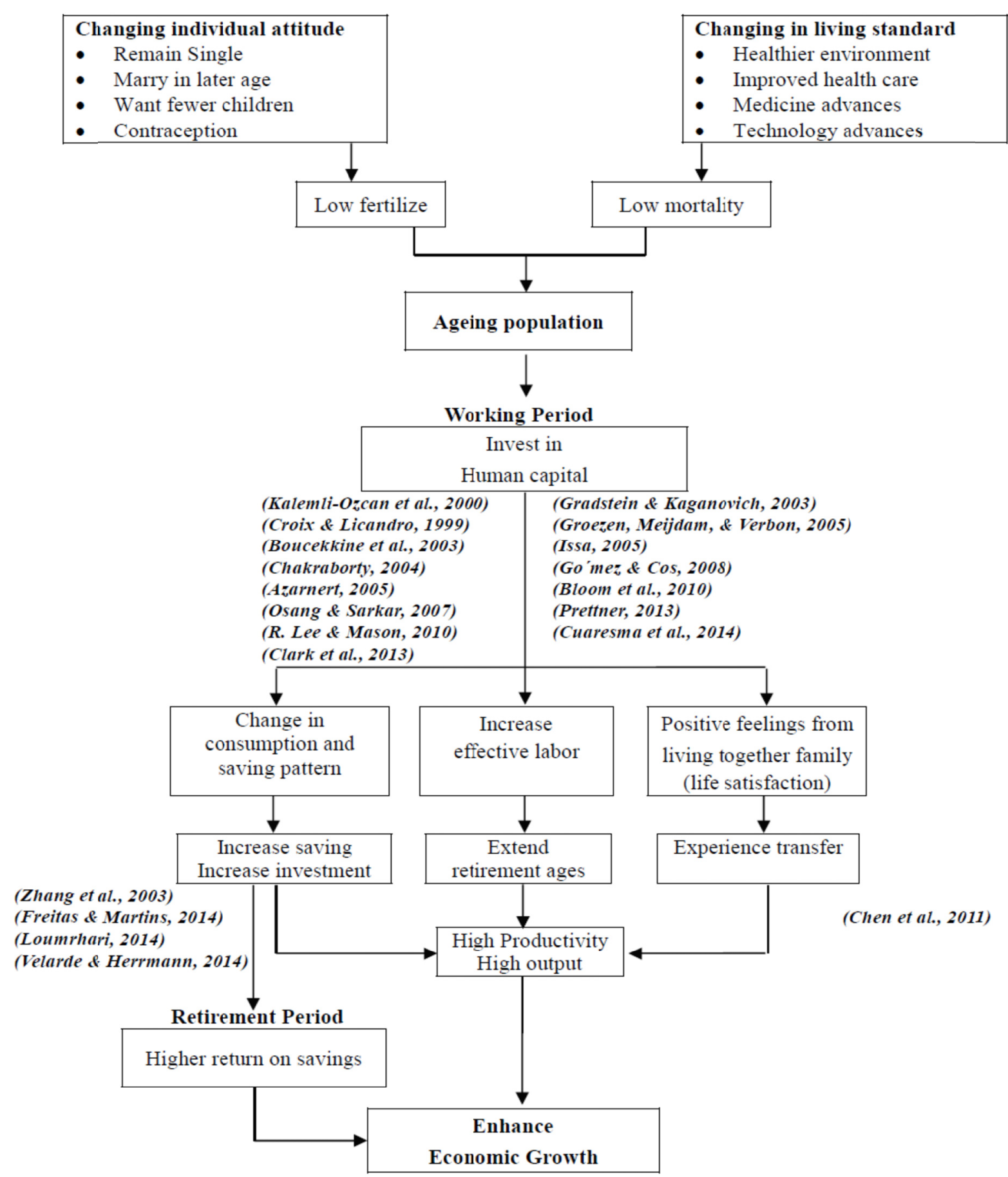

Figure 2. The optimists view of the impact of population ageing on economic growth

Source: Adapted from Sukpaiboonwat, Plyngam, and Jaroensathapornkul (2014)

In contrast to the pessimistic views, the optimists posit that a positive interaction, between economic growth and population ageing, exists. According to this body of literature, since both few children and longer life bring about higher savings in preparation for retirement, older individuals tend to save more. As such, the increase in longevity will not only bring about an upsurge in savings as well as the savings time span, but also provide more resources for investment, which positively impact investment, particularly in Research and Development, which 
is unanimously recognized as the engine of economic growth (Nagarajan, Teixeira, and Silva, 2016). Besides, regarding the problem of increasing deficits in government budgets with its negative attendant on capital accumulation and productivity growth associated with ageing, the optimists hold a contrasting view. Even though ageing, as argued by pessimists, is assumed to exert a negative effect on government budgets, however, the degree of such impact depends on the types of retirement policies that government adopts (Finch, 2014). Nagarajan et al (2016) postulated that as long as retirement policies can be adjusted by moving them to private pension schemes and raising the retirement age and; if the number of immigrant workers can be increased to recompense for the shortfall in the labour force, then it becomes possible to offset the rise in public expenditure associated with ageing.

Intrinsically, from a theoretical standpoint, the effects of population ageing on economic growth are unclear as the juxtaposition of the pessimistic and optimistic views revealed. Besides these theoretical divergences, even empirical literature, more often than not, provided ambiguous results. Some studies (for instance, Lindh, 2004; Davies and Robert, 2006; Fougère, Mercenier, and Mérette, 2009; Narciso, 2010; Bloom, Canning and Fink, 2010; Hashimoto and Tabata, 2010; Sharpe, 2011; Park and Shin, 2012; Walder and Döring, 2012; Lisenkova, Mérette, and Wright, 2012; Navaneetham and Dharmalingam, 2012; Lee, 2014) argued that a country with a higher proportion of population in the old age group tends to be associated with decreasing productivity levels, lower savings, and higher government spending, underlining the political and fiscal pressures that the old-age pension, health care and social protection systems of several countries are likely to face in the upcoming decades. Still, some studies (for instance, Zhang, Zhang, and Lee, 2003; Alders and Broer, 2005; Gomez and De Cos, 2008; Hock and Weil, 2012; Freitas and Martins, 2014; Loumrhari, 2014; Velarde and Herrmann, 2014; Ismail, Rahman, and Hamid, 2015; Acemoglu and Restrepo, 2017) found that the process of ageing is significantly and positively related to cross-country economic performance. As such, the actual consequence of ageing on growth as theorized by the two schools of thought is inconclusive.

Nigeria, like every country in the world, is experiencing growth in the number, share and percentage of the population of the elderly. In 2006, according to National Population Commission (2017), the country's elderly population make up about 4.56 percent ( 6.4 million) of the total population which was put at $140,431,790$. More importantly, this subset of Nigeria's population is expected to begin to grow rapidly around 2030. In particular, according to World Population Prospects (2017), it is expected to reach sixteen (16) million and forty- seven (47) million by 2030 and 2060 respectively. Thus, while the Nigerian society is still characterised by a rather young population, a salient revolution has already started: an increase in the number, share and percentage of the elderly. In this regard, the critical question is this: what are the growth implications of such rapid upsurge in the number of the elderly for Nigeria. This is because, in designing and adopting appropriate policy for Nigeria, an in-depth understanding of ageing phenomenon is essential in order to ensure that potential windfalls are exploited and threats avoided.

Although the literature hold a reservoir of important empirical contributions on the subject, however, aside the fact that there are limited or a total lack of empirical studies on less developed and developing countries as the bulk of the available empirical evidences focused on developed economies, the few existing studies (Asagba, 2005; Mason, 2005; Ajomale, 2007; Bloom, et al, 2010; Lee and Mason, 2014; Fürnkranz-Prskawetz, Lee, Lee, Mason, Miller, Mwabu, and Soyibo, 2013; Nagarajan, Teixeira, and Silva, 2016) are cross-country/cross-section studies. The problem with such discourse is the homogenous supposition across the countries, which is impractical because of difference in culture, institutional, economic and social conditions. As such, country specific study is still missing. This study, thus, investigated empirically the economic growth consequences of population ageing in Nigeria.

The rest of paper is structured as follows. In the next section, a brief overview of the literature on growth-ageing nexus is presented. The following section depicts a theoretical model used to rationalize the nexus between ageing and economic growth and also separate the effects of youth-age dependency and old-age dependency in order not to impose symmetry supposition on the growth of income per capita. Section four (4) describes method of data analysis and estimation techniques used, while section five (5) depicts the data source. Section six (6) shows empirical results and discussion, whereas section seven (7) concludes the paper.

\section{A Brief Literature Review}

In recent years, the debate on whether population ageing enhances or dampens economic growth has been a subject of controversy in economic development discourse. Broadly speaking, there are two contentious schools of thought to this debate, namely; the pessimistic and optimistic theories. The pessimists contend that the inequality in a country's population age structure, particularly, a greater share of the population of the elderly, 
depresses the country's productivity level. According to this school of thought, other than the sharp reduction in labour force and national saving rates which in turn would lessen investment and real output; in an ageing society, fiscal problems which have profound consequences on economic growth, are likely to emerge. A rising old-age dependency ratio will not only translate into growing tax burden, but also, health care and public pension expenditures which will crowd out public investment spending for infrastructure with negative effects for capital accumulation and productivity growth. However, the optimists, in contrast to the pessimistic school of thought, postulate that a positive nexus, between economic growth and population ageing, exists. According to this body of literature, since both few children and longer life bring about higher savings in preparation for retirement, older individuals tend to save more. As such, the increase in longevity will not only bring about an upsurge in savings as well as the savings time span, but also provide more resources for investment, which positively impact investment, particularly in Research and Development, which is unanimously recognized as the engine of economic growth.

Numerous studies have explored the implications of these two propositions. For instance, Zhang, Zhang, and Lee, (2003) examined the impact of declines in adult mortality on growth in an overlapping generations model. With public education and imperfect annuity markets, a decline in mortality affects growth through three channels. First, it raises the saving rate and thereby increases the rate of physical capital accumulation. Second, it reduces accidental bequests, lowers investment, and thereby lowers the rate of physical capital accumulation. Third, it may lead the median voter to increase the tax rate for public education initially but lower the tax rate in a later stage. Starting from a high mortality rate as found in many Third World populations, the net effect of a decline in mortality is to raise the growth rate. However, starting from a low mortality rate such as is found in most industrial populations, the net effect of a further decline in mortality is to reduce the growth rate. Ono (2003) found the ageing lead to a deficit budget when government finances the social security and the tax revenue is deficient. The "pay-as-you-go" scheme would be preferred in this case. However, if the economy slows down, the fair pension scheme would be preferred.

Athukorala and Tsai (2003), in Taiwan, found the significantly negative impact of Taiwanese household saving rate. The saving is necessary for increasing economic growth as the role of accumulation capital. Therefore, the impact of a larger ageing population also diminishes economic growth in the future. Lindh (2004) addressed this question of whether growth will be saved in the ageing society by increasing human capital investment. In the narrow sense of human capital investment, i.e. by increasing years of education the study argued that it will only be a minor part of the solution since any realistic increase in efficiency through education falls far short of what is needed to keep relative living standards of the dependent and active population at anything near current levels. By focusing on the dependency ratio it is emphasized that the problem of ageing is not so much a question of the GDP level per se but of redistribution. No matter what the growth rate is, we either get a decrease in the relative standard of living of the elderly or we have to redistribute a sizable part of productivity growth from the active generation to the elderly. The point of having higher growth in that context is that it makes it easier and more acceptable to achieve the redistribution.

Davies and Robert (2006) studied the role of population ageing for foreign direct investment (FDI) and the strategic taxation of capital. Importantly, their theoretical model suggests that the labour market implications of ageing differ from the financial market aspects. While population ageing may be associated with a lower capital stock in the home country and less foreign direct investment, the effects through the labour market and employment tend to generate larger outbound capital flows. To quantify these aspects, the study conducted regression analysis to empirically document how population ageing affects FDI. To be specific, they used data on both US inbound and outbound FDI. Notably, the estimates between the US and other developed countries conform quite closely to the predictions of their theory. They concluded by studying the strategic taxation of capital. In particular, they examined this issue in light of the fiscal burden associated with older populations. In contrast to previous work on tax competition, the study incorporated that old-age transfer programs are generally funded by labour taxes. In this manner, their framework introduced new insights regarding the incentives for governments to restrict capital outflows since doing so increases the labour income tax base used for intergenerational transfers. Finally, the study argued that foreign firms will not invest in a country with an ageing population since the working age population is scarce, consequently negatively affecting the country's capability to produce wealth.

Gomez and De Cos (2008) addressed this question of whether divergent demographic trends can account for differences in per capita output across countries by offering evidence that the process of population ageing is positively and significantly related to cross-country economic performance. The study defined and estimated the effect of demographic change in two ways. First, a growing cohort of working age persons (15-64) as a share of 
the total population is found to have a large positive effect on GDP per capita. Second, an increase in the number of prime age persons (35-54) relative to the younger working age population (15-34) is found to have a positive but curvilinear effect with respect to per capita GDP. Also, the study found that changes in per capita GDP peak when the ratio of the prime-to-younger age population reaches an optimum of prime age workers for every younger aged worker. Beyond or below this optimal ratio, per capita output is lowered.

Fougère, Mercenier, and Mérette (2009) explored the long-term impact of population ageing on labour supply and human capital investment in Canada, as well as the induced effects on productive capacity. The analysis was conducted with a dynamic computable overlapping generation model. The paper indicated that population ageing created more opportunities for young individuals to invest in human capital and supply more skilled labour at middle age. Consequently, the reduction in labour supply of young adults initially lowers productive capacity and exacerbates the economic costs of population ageing. However, current and future middle-age cohorts are more skilled and work more, which eventually raises productive capacity and significantly lowers the cost of population ageing. Finally, these results suggest that the recent increase in the participation rate of older workers might be the beginning of a new trend that will amplify over the next decades. Since the greater number of elderly need more healthcare, Hashimoto and Tabata (2010) investigated the relationship between ageing, health and economic growth by using an overlapping-generations model. The study found the ageing diminishes the economic growth in small economies because the rising demand in health care due to the rising number of elderly people increases employment in the health sector. However, Aisa and Pueyo (2013) contended that it has an ambiguous effect. Though the greater number of elderly people affects the shift of labor in the health sector, the role of capital accumulation also shifts the demand in the non-health sector because of the reducing income of elderly and their demand for health care.

Bloom, Canning and Fink, (2010) examined the effects of population ageing on economic growth. They began with a presentation and analysis of descriptive statistics on the extent and pace of population ageing and then explored the overall effect of population ageing on economic growth as well as the effects operating via two main channels through which growth can occur: labour supply and human capital accumulation. Accounting effects of population ageing on factor accumulation and economic growth are distinguished from behavioral effects. This paper analyses the implications of population ageing for economic growth. Their main conclusion is that population ageing poses challenges that are formidable, but not insurmountable. Narciso (2010) analyzed the impact of ageing on foreign direct investments (FDI) and foreign portfolio investments (FPI) on a bilateral level. First of all, the study presented a theoretical foundation of the relationship and then tested it by an empirical model. Theoretical foundations are based on the lifecycle hypothesis and overlapping generation model in a demographic context. The bilateral FDI and FPI are modelled by using fixed effects balanced panel data. The results suggested that the current and future age structure of the nation has significant effect on current international capital flows.

Cervellati and Sunde (2011) addressed the effect of life expectancy on economic growth and highlighted the significance of accounting for the non-linearities and non-monotonic features of the demographic transition when modelling such a link. They documented a hump-shaped relationship between life expectancy and population growth and show that increases in life expectancy accelerate income per capita in countries that have already experienced the onset of the transition by 1940, while the effect does not exist in pre-transitional countries. Sharpe (2011) provided a detailed examination of the relationship between ageing and productivity. While the author found some evidence of a negative effect of ageing on productivity, however, the study concluded that at the aggregate level the effect is small. Hock and Weil (2012) examined the effects of population ageing due to declining fertility and rising elderly life expectancy on consumption possibilities in the presence of intergenerational transfers. Their analysis was based on a highly tractable continuous-time overlapping generations model in which the population is divided into three groups (youth dependents, workers, and elderly dependents) and life course transitions take place in a probabilistic fashion. They showed that the consumption-maximizing response to greater longevity in highly developed countries is an increase in fertility. However, with larger transfer payments, the actual fertility response will likely be the opposite, leading to further population aging.

Lisenkova, Mérette, and Wright (2012) presented a dynamic Overlapping Generations Computable General Equilibrium (OLG-CGE) model of Scotland. The model was used to examine the impact of population ageing on the labour market. More specifically, it was used to evaluate the effects of labour force decline and labour force ageing on key macroeconomic variables. The second effect is assumed to operate through age-specific productivity and labour force participation. In the analysis, particular attention is paid to how population ageing impinges on the government expenditure constraint. The basic structure of the model follows in the Auerbach 
and Kotlikoff tradition. However, the model takes into consideration directly age-specific mortality. This is analogous to "building in" a cohort-component population projection structure to the model, which allows more complex and more realistic demographic scenarios to be considered. Park and Shin (2012) argued that the demographic dividend that contributed substantially to economic growth in developing Asia in the past is dissipating as population ageing affects growth through savings, capital accumulation, labour force participation, and total factor productivity. They examined the impact of ageing on those four channels in 12 developing Asian economies that collectively make up the bulk of the region's population and output. The study then made projections about the effects of demographic change on the economic growth of the 12 from 2011 to 2020 and from 2021 to 2030. The results obtained indicated that there will be a sizable adverse economic impact where population ageing is more advanced.

Walder and Döring (2012) argued that the degree of inequality regarding the population age structure of a country impacts on the consumption pattern of its households. Due to the ageing problem, the overall demand for certain goods will be affected, since they will not provide any utility for the older household. For instance, in a country with a high old age population, the overall demand for education will decline as the consumption preferences of the old age group fall more on medical care. Prettner (2013) posited that older individuals tend to save more. As a result, they provide more resources for investment, which positively affects economic growth. In fact, the rise in longevity will positively influence investment, particularly in $R \& D$ which is generally recognized as an engine for economic growth (Aghion and Howitt, 1992). Loumrhari (2014) investigated empirically the relationship between population ageing and private savings in Morocco. To do this, the paper used an overlapping generations model (OLG) using annual data from 1980 to 2010. Econometric estimates show that if the increase in the dependency ratio negatively affects the growth rate of savings, as predicted by the lifecycle theory, longevity to the contrary tends to stimulate the same savings. However, it seems that the first effect outweighs the second. Economic policies to promote private savings and incentives for households to have more children are needed to meet the challenge of severe aging population which will face Morocco in the coming decades.

Freitas and Martins (2014) analyzed the impact of health, pension systems and longevity on savings. The study used a simple life-cycle model embodying social transfers (health care and pension expenditures) and changes in longevity to determine the level of household savings. From this model, they derived an econometric specification, augmented with the effects of public budget balances. The model was estimated for a panel of 22 OECD countries for the period 1970-2009. Their principal result was that, from the point of view of incentive to save, health transfers have a similar impact as pension replacement rates. Thus, welfare reforms that reduce replacement rates without reforming health system may not have all the expected impact on household savings. In line with life-cycle theory, they found that longevity increases saving ratios. In order to test whether a retirement-consumption puzzle does exist, Velarde and Herrmann (2014) examined how food-related time use alters within the $50+$ generation in Germany due to retirement. Based on the German Time-Use Survey, time-use patterns of retired and non-retired persons are compared statistically and determinants of time-use are elaborated by the use of double-hurdle and multiple regression models. With retirement, major changes take place in the food-related time use. Work-related food-away-from-home consumption is substituted by food production and consumption at home and associated shopping activities. Leisure-related away-from-home consumption gains importance for a portion of pensioners. These impacts are strong and highly significant for German households. By and large, there is no indication of a retirement-consumption puzzle but of a planned behavioral change in a new phase of life. Econometric analysis showed that other personal and socio demographic variables explain food-related time use patterns in the 50+ generation, in particular gender, age, perceived health and the educational level attained.

Ismail, Rahman, and Hamid (2015) examined the impact of ageing on economic growth. The study used dynamic growth model and employed ARDL approach for the period of 1970 to 2013. Three proxies for ageing are used namely fertility rate, life expectancy and old dependency ratio. However, only fertility rate detect to have a long run cointegration. The major findings of this study revealed that a reduction of fertility rate lead to higher economic growth. This implied that even though Malaysia will face ageing society by 2020, the economic growth still stable and can increase by investing more on human capital. Maestas, Mullen, and Powell (2016) started from the observation that many U.S. states have already experienced substantial growth in the size of their older population and much of this growth was predetermined by historical trends in fertility. The study, thus, used predicted variation in the rate of population ageing across U.S. states over the period 1980-2010 to estimate the economic impact of ageing on state output per capita and found that a $10 \%$ increase in the fraction of the population ages $60+$ decreases the growth rate of GDP per capita by $5.5 \%$. Two-thirds of the reduction is due to 
slower growth in the labour productivity of workers across the age distribution, while one-third arises from slower labour force growth. Their results imply annual GDP growth will slow by 1.2 percentage points this decade and 0.6 percentage points next decade due to population ageing.

Acemoglu and Restrepo, (2017) contended that several theories have emphasized the negative effects of an ageing population on economic growth, either because of the lower labor force participation and productivity of older workers or because ageing will create an excess of savings over desired investment, leading to secular stagnation. They showed that there is no such negative relationship in the data. If anything, countries experiencing more rapid ageing have grown more in recent decades. They suggest that this counterintuitive finding might reflect the more rapid adoption of automation technologies in countries undergoing more pronounced demographic changes, and provide evidence and theoretical underpinnings for this argument.

Wei, Zhu, and Glomsrod (2018) posited that population ageing will accelerate in the coming decades in China and this may have considerable impact on the economy and energy-related emissions, potentially affecting the global economy and global climate. By using a global computable general equilibrium (CGE) model they explored the impact caused by the population ageing through imposing the expected 2050 age structure on the economy and population size of 2011. Results showed that gross domestic product (GDP) of China is reduced by nearly $10 \%$ as the ageing reduces consumption, labour supply and investments. However, increasing returns to capital abroad adds support to domestic demand. Ageing process in other countries can double ageing impacts on domestic consumption and encourage only a few production sectors in China. Global energy-related emissions is reduced by $700 \mathrm{Mt}$ carbon dioxide (or about $70 \%$ of the 2011 emissions in Japan) due to the population ageing in China.

In sum, from the review of empirical literature above, it is evident that there is no clear consensus on the nexus between economic growth and population ageing. Amid the theoretical ambiguity, even the empirical findings on the nexus is also far from conclusive. Apart from this, the review of the literature, in addition also revealed that while a large number of empirical studies have attempted to explore the growth-ageing nexus; however most of such empirical literature have been based on cross-country data for a particular region or for all countries with available data. The problem with such studies is the homogenous assumption across the countries, which is unrealistic because of difference in culture, social, economic and institutional conditions. As such, country specific studies are needed to fill the gap.

\section{Theoretical Model}

In this section, in order to provide a model to be used in investigating the economic growth consequences of population ageing in Nigeria, this study, though augmented by certain improvements and extensions by taking into account the objective of the study, adopted the work of Bloom and Williamson (1998), Bloom, Canning and Malaney (1999, 2000), and Bloom, Canning, and Finlay (2010), draws on the theoretical framework of neoclassical growth model and assumes a production function of the form:

$$
Q=A K^{\alpha} L^{1-\alpha}
$$

where $A, K, L, \alpha$ and $Q$ are TFP (i.e total factor productivity), capital, labour force, elasticity of output with respect to capital and output respectively. Following Bloom et al $(1999,2000)$, supposing the endogenous processes which generate physical capital accumulation and TFP converge to a steady state, then the steady-state output per worker, $q^{*}$, is derived as follows:

$$
\left(\frac{Q}{L}\right)^{*}=A\left(\frac{K^{*}}{L}\right)^{\alpha} \Rightarrow q^{*}=A k^{* \alpha}
$$

Supposing this steady-state value $\left(q^{*}\right)$ is determined by a set of factors, $\Omega$ (that is a matrix of variables), that may affect TFP and physical capital accumulation. That is,

$$
q^{*}=\Omega \theta
$$

Given the model (3), the regression equation derived from this model assumes that the actual level of income per worker will adjust slowly from its initial level to this steady-state level as follows: 


$$
g_{(q)}=\gamma\left(q^{*}-q\right)
$$

Where

$g_{q}=$ growth rate of output per worker

$q^{*}=$ natural $\log$ of the steady state of per worker output

$q$ = natural $\log$ of the initial per worker output

$\gamma=$ the rate of convergence.

Equation (4) suggests that a country's rate of growth is directly proportional to the initial distance from its steady-state income level $q^{*}$. As such, the poorer a country is with respect to its steady state, the faster such country is expected to grow. As argued in Bloom et al (1999, 2000), this property of standard neoclassical growth models, in which each country's income continually approaches a ceiling that is determined by that country's characteristics, is known as conditional convergence (see, for example, Barro, 1991; Mankiw, Romer, and Weil, 1992; Barro and Lee, 1994; Barro and Sala-I-Martin, 1995; Sachs, Warner, Åslund, and Fischer, 1995). Again, following Bloom et al (1999, 2000), the steady-state equation is substituted into the adjustment process as follows:

$$
g_{(q)}=\gamma(\Omega \theta-q)
$$

where $\theta$ is a vector of parameters. Equations (1-5) provide the theoretical underpinnings of most recent empirical studies of the sources of economic growth. While these equations are usually specified in terms of output per worker; however, empirically the equations are usually written in terms of per capita income. As argued in Bloom and Williamson (1998) this practice is valid only for demographically stable populations. Hence, once the age structure of the population is undergoing a transition, interpreting equation (5) in per capita terms is no longer valid. Thus, in order to investigate the economic growth consequences of population ageing equation (5) is transformed from output per worker, $q$, to output per capita, $\hat{q}$. Consider the following simple identity:

$$
\frac{Q}{N}=\frac{Q}{L} \frac{L}{W} \frac{W}{N}
$$

where $N, L$, and $W$ denote the population, the labour force and the working age population respectively. Equation (6) states that per capita income equals labour productivity $\left[\frac{Q}{L}\right]$ multiply by the absorption rate $\left[\frac{L}{W}\right]$ multiply by the working age ratio $\left[\frac{W}{N}\right]$. For simplicity, supposing the absorption rate is constant. Deriving equation (6) in terms of growth rate,

$$
g_{\left(\frac{Q}{N}\right)}=g_{\left(\frac{Q}{L}\right)}+g_{\left(\frac{W}{N}\right)}
$$


As for the growth rate of income per worker $\left(g_{\left(\frac{Q}{L}\right)}\right)$, this is explained by the convergence term in (5). Conversely, as for the growth rate of the working age ratio $\left(g_{\left(\frac{W}{N}\right)}\right)$, the study, following Bloom et al (2010), separated the effects of youth-age dependency and old-age dependency in order not to impose symmetry assumption on the growth of income per capita. Thus, the study want to identify,

$$
g_{\left(\frac{Q}{N}\right)}=g_{\left(\frac{Q}{L}\right)}+g_{\left(\frac{N-Y-A}{N}\right)}
$$

where $N, Y$, and $O$ are population, youth-age dependency and old-age dependency respectively; and the working age share equals the population less the youth-age dependency and old-age dependency. In order to isolate the growth of the youth-age dependency and old-age dependency, the study draws on rules of approximation as follows. Given that

$$
g_{\left(\frac{W}{N}\right)} \approx \ln \left(\frac{W}{N}\right)_{t}-\ln \left(\frac{W}{N}\right)_{0}
$$

Then, the growth rate of the working age is redefined as follows

$$
g_{\left(\frac{N-Y-A}{N}\right)}=\ln \left(\frac{N-Y-A}{N}\right)_{t}-\ln \left(\frac{N-Y-A}{N}\right)_{0}
$$

The approximation accuracy of $\ln (1-p) \approx p$ is increasing in the working- age share, and using this approximation to assert that,

$$
\begin{gathered}
g\left(\frac{N-Y-A}{N}\right)=-\left(\frac{Y+A}{N}\right)_{t}+\left(\frac{Y+A}{N}\right)_{0} \\
g\left(\frac{N-Y-A}{N}\right)=\frac{Y}{N_{0}}-\frac{Y}{N_{t}}+\frac{A}{N_{0}}-\frac{A}{N_{t}}
\end{gathered}
$$

Now, substituting (5) and (12) into (8), and also employing the fact that

$$
\hat{q}=\log \left(\frac{Q}{N}\right), q=\log \left(\frac{Q}{L}\right), b=\log \left(\frac{L}{W}\right), w=\log \left(\frac{W}{N}\right)
$$

and the fact that taking the logs of both sides of equation (6) gives $\hat{q}=q+b+w$, the study obtained

$$
\begin{gathered}
g_{(\hat{q})}=\gamma(\Omega \theta-\hat{q}+b+w)+\frac{Y}{N_{0}}-\frac{Y}{N_{t}}+\frac{A}{N_{0}}-\frac{A}{N_{t}} \\
g_{(\hat{q})}=\gamma(\Omega \theta-\hat{q}+w+b)-\left[\frac{Y}{N_{t}}-\frac{Y}{N_{0}}\right]-\left[\frac{A}{N_{t}}-\frac{A}{N_{0}}\right]
\end{gathered}
$$

where 
$g_{(\hat{q})}=$ growth rate of output per capita

$\gamma=$ rate of convergence

$\theta=$ vector of parameters and

$\Omega=$ matrix of variables that affect the steady-state levels of capital intensity and TFP.

Given the above backdrop, equation (15) will form the base of the empirical strategy. Here growth rate of per capita real GDP is dependent on the income per capita, working age population share, absorption rate, change in youth age dependency, change in adult age dependency, and other variables affecting human productivity. In this paper, the study is not interested in the absorption rate and thus assumes that it will be captured in the constant term of the empirical exercise carried out. By substituting $\Delta Y^{*}=\left[\frac{Y}{N_{t}}-\frac{Y}{N_{0}}\right]$ and $\Delta A^{*}=\left[\frac{A}{N_{t}}-\frac{A}{N_{0}}\right]$, and adding, a white noise residual $\mathcal{E}$ gives the following equation:

$$
g_{(\hat{q})}=\gamma \Omega \theta-\gamma \hat{q}-\not w-\Delta Y^{*}-\Delta A^{*}+\varepsilon
$$

Hence, an econometric representation of equation (16) is given below:

$$
g_{(\hat{q})}=\beta_{0}+\beta_{1} \hat{q}+\beta_{2} w+\beta_{3} \Delta Y^{*}+\beta_{4} \Delta A^{*}+\beta_{5} \Omega+\varepsilon
$$

To close the model there is the need for variables in vector $\Omega$ (a set of factors that determined the steady state level of income) to be defined. As noted in the literature the typical variables usually included in the vector $\Omega$ are gross capital formation, a measure of institutional quality, life expectancy, average years of secondary schooling, a measure of trade openness, geographic variables, and so on.

Following Bloom et al (2010) and by also taking cognizance of the objective of the study, equation (17) is augmented by inserting life expectancy at birth and human capital accumulation variables. In the context of the literature, the conventional standard usually used to measure human capital accumulation has been largely categorized into three parts: income-based, output-based, and cost-based approaches. Income-based approach is carefully linked to the individual's benefits obtained by training and education investment. Moreover, cost-based approach is built on calculating costs paid for obtaining knowledge. Average years of schooling, scholastic attainments, school enrollment rates, and adult literacy e.t.c are the some examples of output-based approach.

Various studies have used different variables as proxies for education. The central reason for this, apart from the difference in conceptualizing education, has been the lack of reliable data, particularly for developing countries, including Nigeria. Usually, however, gross enrollments and average years of education are the two most commonly used variables as proxy for education: In this study, gross (total) enrollments are incorporated as a proxy for human capital. The key reason for this, besides the paucity of specific data on average years of schooling as well as scholastic attainments and adult literacy, is that the study is interested in the total coverage of an educational system in relation to the population eligible for participation in the system.

Regarding the impact of life expectancy on economic growth, Cervellati and Sunde (2010) argued that, life expectancy, just like change in old-age dependency population, can have both negative and positive impacts on the economic growth. At one end of this debate, in countries undergoing demographic transition, the main effect of an increase in life expectancy is to accelerate population growth, which tends to reduce per capita income, while there is little effect on education. At the other end of this debate, in countries that have completed the transition an increase in life expectancy lessen population growth, accelerate human capital formation as well as incentive for people to save for their extended period of retirement and, thus, increase per capita income. Thus, in order to examine the dynamic linkage between Nigeria's economic growth and ageing, following Ismail, Rahman, and Hamid (2015) two proxies for ageing are used namely, life expectancy at birth and change in old-age dependency population. 
Hence, following Sankay, Ismail, Shaari (2010), to empirically investigate the economic growth consequences of population ageing in Nigeria, the basic model that was estimated consist of seven variables explicitly written as follows:

$\delta \ln R G D P_{t}=\alpha_{0}+\alpha_{1} \ln P C I_{t}+\alpha_{2} \ln W A S_{t}+\alpha_{3} \ln Y A D_{t}+\alpha_{4} \ln O A D_{t}+\alpha_{5} \ln T S E_{t}+\alpha_{6} \ln L E A B+\varepsilon_{t}$

Accordingly, the basic econometric model (equation 18) that was estimated captured the impacts of all age groups on economic growth. Where $\delta \ln R G D P, \ln P C I, \ln W A S, \ln Y A D, \ln O A D, \ln T S E$, and $\ln L E A B$

are per capita real GDP growth rate, income per capita, initial share of working age, change in youth age dependency, change in adult age dependency, human capital accumulation and life expectancy at birth. In order to eliminate or lessen significantly any heteroskedasticity in the residuals of the estimated model all the variables are transformed to their natural logarithm form. The paper used E-Views (9) econometric software for all the data analyses carried out in this study.

\section{Estimation Techniques and Method of Data Analysis}

Given the model (18), Innovation Accounting Technique was applied. Precisely, in order to investigate the economic growth consequences of population ageing in Nigeria, a four-step procedure was employed. In the first stage, the study tested for the stationarity status of the employed variables. Although, the ARDL and TYDL approaches do not require pre-testing of the variables included in the model, nevertheless testing for unit root is still worthwhile for two main reasons. First of all, testing for unit root is necessary to avert spurious regression problem. Secondly, testing for the unit root helps to select maximum likely order of integration $\left(\mathrm{d}_{\max }\right)$ of the series in the system.

In the second stage, the structural lags were determined on the basis of Hannan-Quinn information criteria (HQ), the Akaike information criteria (AIC), the Schwarz information criteria (SIC), the Log Likelihood (LL) and the Final Prediction Error (FPE). Premise on the suggestion of Granger (1988), in the third stage, a test of possible cointegrating relationship among the series was conducted. Essentially, the newly proposed ARDL model is utilized to check co-integration and to estimate short run and long run relationships. Compared with other cointegration procedures this method has basic econometric advantages. To start with, this method is applicable irrespective of whether the underlying variables are purely $\mathrm{I}(0), \mathrm{I}(1)$ or mixture of both thereby averts the pre-testing of the order of integration of the variables. Besides, the both the short-run and long-run parameters of the model can be estimated simultaneously. Further, the method is more robust and does better for small sample sizes. In addition, even when some of the regressors are endogenous, this approach generally provides unbiased estimates of the long-run model and valid t-statistic (Harris and Sollis, 2003). Keeping in view the above advantages, the augmented ARDL-UECM version of the model (18) specified earlier is expressed as:

$$
\begin{aligned}
& \Delta\left(\delta \ln R G D P_{t}\right)=\delta_{0}+\psi_{1}\left(\delta \ln R G D P_{t-1}\right)+\psi_{2}\left(\ln P C I_{t-1}\right)+\psi_{3}\left(\ln W A S_{t-1}\right)+\psi_{4}\left(\ln Y A D_{t-1}\right)+\psi_{5}\left(\ln O A D_{t-1}\right)+ \\
& \psi_{6}\left(\ln T S E_{t-1}\right)+\psi_{7}(\ln L E A B)+\sum_{i=1}^{a} \theta_{i}\left(\delta \ln R G D P_{t-i}\right)+\sum_{i=0}^{b} \beta_{i}\left(\ln P C I_{t-i}\right)+\sum_{i=0}^{c} \lambda_{i}\left(\ln W A S_{t-i}\right)+\sum_{i=0}^{d} \phi_{i}\left(\ln Y A D_{t-i}\right)+ \\
& +\sum_{i=0}^{e} \varpi_{i}\left(\ln O A D_{t-i}\right)+\sum_{i=0}^{f} \Omega_{i}\left(\ln T S E_{t-i}\right)+\sum_{i=0}^{g} \rho_{i}\left(\ln L E A B_{t-i}\right)+U_{t}
\end{aligned}
$$

where $\delta_{0}$ is the drift component, $\Delta$ is first-difference operator, while $a, b, c, d, e, f$ and $g$ are the optimal lag lengths for each incorporated series. Note that the approach could have varying lag orders. The second part of the equation with $\theta_{i}, \beta_{i}, \lambda_{i}, \phi_{i}, \varpi_{i}, \Omega_{i}$ and $\rho_{i}$ represents the short-run dynamic multipliers of the model whereas the parameters $\psi_{i}$ 's represent the long-run multipliers. Note that the terms with summation signs are used to model the short-run dynamic structure. 
Thus, from equation (19) in applying cointegration tests the study test the null hypothesis of no cointegration

$$
H_{0}: \psi_{1}=\psi_{2}=\psi_{3}=\psi_{4}=\psi_{5}=\psi_{6}=\psi_{7}=0 \quad \text { against the alternative hypothesis }
$$

$$
H_{1}: \psi_{1} \neq \psi_{2} \neq \psi_{3} \neq \psi_{4} \neq \psi_{5} \neq \psi_{6} \neq \psi_{7} \neq 0 \text {. }
$$

Having estimated our unrestricted error correction ARDL models, the Wald test based on the standard $F$-statistic was computed to establish the co-integration relationship among the variables of interest. Due to limitations of the conventional Wald-test F-statistic, Pesaran, Shin and Smith (2001) have suggested two critical values (lower and upper bound) to examine the relationship. Therefore, when the computed $F$-statistics is greater than the upper bound value, it implies existence of long-run relationship among the variables. On the contrary, when the computed $F$-statistic is less than the lower bound value, the null is not rejected. Lastly, when the computed $F$ statistics lies between the lower bound and upper bound, long run association between the variables becomes inconclusive.

In stage four, besides the benefits of data description and forecasting as well as structural inference and policy analysis, in order to avert the drawbacks of endogeneity and integration of variables, the study adopts Vector Autoregression (VAR) modelling framework. In the literature, there are different extensions of VAR models developed to capture the underlying statistical features of the series under examination. Among the prominent extensions are the: VAR model in the first-differenced data, VAR Model in the level data (VARL), Vector Error Correction Model (VECM) and TYDL approach of Toda, Yamamoto, Dolado and Lutkepoh. But, as argued Hundie (2014), the Vector Error Correction Model technique which usually involves pre-testing through unit root and cointegration tests suffers from size distortions and often can lead to mistaken conclusions about causality. Conversely, Philips and Toda $(1993,1994)$ contended that Vector Autoregression (VAR) estimation often contains nuisance parameters and then no satisfactory basis for mounting a statistical test of causality test applies as the F-test statistic does not have a standard distribution when variable are integrated.

Keeping the above limitations in view, this study, following Hundie (2014), embraced the Toda and Yamamoto (1995) and Dolado and Lutkepoh (1996)-TYDL approach. This method has many advantages over other methods. Aside the fact that the method better controls the types I error probability than other methods; the technique is appropriate regardless of integration and cointegration properties of model. Besides, the simulation results by Yamada and Toda (1998) reveal that among all the techniques, it is the most stable approach. The simple ideas behind the TYDL is to augment the correct VAR order, $p$, with $d_{\max }$ extra lags, where $d_{\max }$ equals the maximum likely order of integration of the series in the system. Hence, the augmented VAR version of equation (18) is given below:

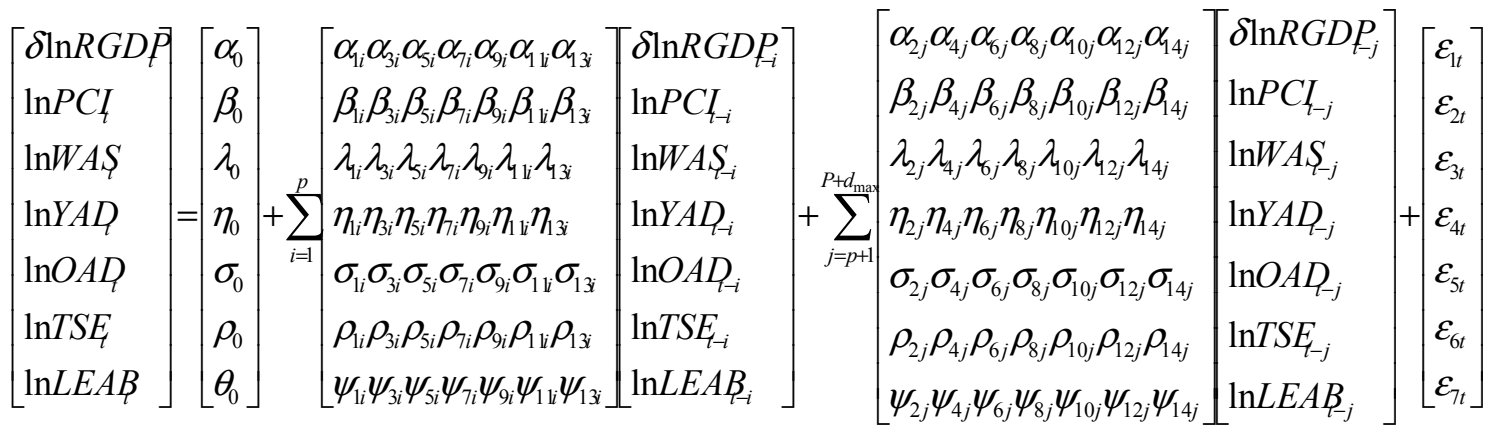

Hence, given the augmented VAR model (20), unlike the previous Granger Causality literature, in order to provide an intuitive insight into the economic growth consequences of population ageing in Nigeria, innovation accounting technique (i.e. forecast error variance decomposition (FEVD hereafter) and impulse response function (IRF henceforth)) was carried out. As argued in Enders (2008), FEVD allows inferences to be drawn concerning the proportion of the movement in a particular time-series that is attributable to 'shocks' arising from other variables and its own earlier 'shocks' in the VAR, while IRF traces out the time path variable. Together, these two are out-of-sample tests. They are very useful in discerning the dynamic responses of the variables beyond the sample period and the degree of exogeneity of the variables. Besides, in to check the adequacy of VAR model a variety of formal diagnostic tests such as stability, autocorrelation, heteroskedasticity, and non-normality tests were conducted. 


\section{Data Source}

The study made use of secondary data sourced majorly from the publications of Central Bank of Nigeria (CBN) Statistical Bulletin (2016), Africa Development Indicators (2016), and World Development Indicators (2017).

\section{Results and Discussion}

\subsection{Unit Root Test Results}

Before detailed analysis of the study was undertaken, first of all, the stochastic characteristics of the variables was investigated using the Phillips Perron (PP) and Augmented Dickey-Fuller (ADF) tests to determine whether the variables were stationary. The choice of these two test statistics is informed by the fact that both tests control for higher-order autocorrelation. Both tests statistics were done for two alternative specifications (with intercept but no trend and with both intercept and trend) at 5\% level of significance. The null hypothesis for both ADF and PP claims that the data series under examination has unit root while the alternative hypothesis claims that the series is stationary. The result of the ADF and PP tests at level and first difference are reported in tables 1 and 2. As can be seen from the tables both tests consistently suggest that apart from the growth rate of per capita real GDP, which is stationary at level, all other variables (income per capita, share of working age, youth age dependency, adult age dependency, human capital accumulation and life expectancy at birth) become stationary when converted to first differences, suggesting that each is integrated of order one, denoted as I (1).

Table 1. Result for the Augmented Dickey-Fuller Unit Root Test

\begin{tabular}{|c|c|c|c|c|c|c|c|c|c|}
\hline \multicolumn{10}{|c|}{ Augmented Dickey-Fuller (ADF) test with intercept only } \\
\hline \multirow[t]{2}{*}{ Variables } & \multicolumn{4}{|c|}{ Level } & \multicolumn{5}{|c|}{$1^{\text {st }}$ Difference } \\
\hline & Test Statistic & Critical values & P-value & Remarks & Test Statistic & Criti & ical values & P-value & Remarks \\
\hline \multirow{3}{*}{$\delta \ln R G D P$} & & $1 \% \quad-3.584743$ & \multirow{3}{*}{$0.0000^{* * *}$} & \multirow{3}{*}{$\mathrm{I}(0)$} & \multirow{3}{*}{---} & & --- & \multirow{3}{*}{---} & \multirow{3}{*}{---} \\
\hline & -5.856896 & $5 \% \quad-2.928142$ & & & & & --- & & \\
\hline & & $10 \% \quad-2.602225$ & & & & & --- & & \\
\hline \multirow{3}{*}{$\operatorname{Ln} \mathrm{PCI}$} & \multirow{3}{*}{0.261832} & $1 \% \quad-3.584743$ & \multirow{3}{*}{0.9736} & \multirow{3}{*}{ NS } & \multirow{3}{*}{-5.900156} & $1 \%$ & -3.588509 & \multirow{3}{*}{$0.0000 * * *$} & \multirow{3}{*}{$\mathrm{I}(\mathrm{I})$} \\
\hline & & $5 \% \quad-2.928142$ & & & & $5 \%$ & -2.929734 & & \\
\hline & & $10 \% \quad-2.602225$ & & & & $10 \%$ & -2.603064 & & \\
\hline \multirow{3}{*}{ LnWAS } & \multirow{3}{*}{-1.539903} & $1 \% \quad-3.615588$ & \multirow{3}{*}{0.5029} & \multirow{3}{*}{ NS } & \multirow{3}{*}{-5.367918} & $1 \%$ & -3.615588 & \multirow{3}{*}{$0.0000 * * *$} & \multirow{3}{*}{$\mathrm{I}(\mathrm{I})$} \\
\hline & & $5 \% \quad-2.941145$ & & & & $5 \%$ & -2.941145 & & \\
\hline & & $10 \% \quad-2.609066$ & & & & $10 \%$ & -2.609066 & & \\
\hline \multirow{3}{*}{$L n Y A D$} & \multirow{3}{*}{-1.250159} & $1 \% \quad-3.621023$ & \multirow{3}{*}{0.6421} & & & $1 \%$ & -3.615588 & & \\
\hline & & $5 \% \quad-2.943427$ & & NS & -5.234764 & $5 \%$ & -2.941145 & $0.0001 * * *$ & $\mathrm{I}(\mathrm{I})$ \\
\hline & & $10 \% \quad-2.610263$ & & & & $10 \%$ & -2.609066 & & \\
\hline & & $1 \% \quad-3.610453$ & & & & $1 \%$ & -3.610453 & & \\
\hline $\operatorname{LnOAD}$ & -0.467902 & $5 \% \quad-2.938987$ & 0.8868 & NS & -3.001743 & $5 \%$ & -2.938987 & $0.0435 * * *$ & $\mathrm{I}(\mathrm{I})$ \\
\hline & & $10 \% \quad-2.607932$ & & & & $10 \%$ & -2.607932 & & \\
\hline & & $1 \% \quad-3.584743$ & & & & $1 \%$ & -3.588509 & & \\
\hline $\operatorname{LnTSE}$ & -2.227472 & $5 \% \quad 2.928142$ & 0.0648 & NS & -6.042586 & $5 \%$ & -2.929734 & $0.0000 * * *$ & $\mathrm{I}(1)$ \\
\hline & & -2.602225 & & & & $10 \%$ & -2.603064 & & \\
\hline & & $1 \% \quad-3.610453$ & & & & $1 \%$ & -3.626784 & & \\
\hline $\operatorname{LnLEAB}$ & 1.581695 & $5 \% \quad-2.938987$ & 0.9992 & NS & -4.160387 & $5 \%$ & -2.945842 & $0.0025 * * *$ & $\mathrm{I}(\mathrm{I})$ \\
\hline & & $10 \% \quad-2.607932$ & & & & $10 \%$ & -2.611531 & & \\
\hline & & Augmented D & key-Fuller (A & F) test & trend and int & cept & & & \\
\hline & & $1 \% \quad-4.175640$ & & & & & --- & & \\
\hline$\delta \ln R G D P$ & -6.030733 & $5 \% \quad-3.513075$ & $0.0000 * * *$ & $\mathrm{I}(0)$ & --- & & --- & --- & --- \\
\hline & & $10 \quad-3.186854$ & & & & & --- & & \\
\hline & & $1 \% \quad-4.175640$ & & & & $1 \%$ & -4.180911 & & \\
\hline $\operatorname{LnPCI}$ & -0.203110 & $5 \% \quad-3.513075$ & 0.9911 & NS & -6.529477 & $5 \%$ & -3.515523 & $0.0000 * * *$ & $\mathrm{I}(1)$ \\
\hline & & $10 \% \quad-3.186854$ & & & & $10 \%$ & -3.188259 & & \\
\hline & & $1 \% \quad-4.219126$ & & & & $1 \%$ & -4.219126 & & \\
\hline LnWAS & -1.894843 & $5 \% \quad-3.533083$ & 0.6376 & NS & -3.793836 & $5 \%$ & -3.533083 & $0.0279 * * *$ & $\mathrm{I}(\mathrm{I})$ \\
\hline & & $10 \%-3.198312$ & & & & $10 \%$ & -3.198312 & & \\
\hline
\end{tabular}




\begin{tabular}{|c|c|c|c|c|c|c|c|c|c|c|}
\hline \multirow{3}{*}{ LnYAD } & \multirow{3}{*}{0.834353} & $1 \%$ & -4.226815 & \multirow{3}{*}{0.9997} & \multirow{3}{*}{ NS } & \multirow{3}{*}{-5.070026} & $1 \%$ & -4.219126 & \multirow{3}{*}{$0.0011 * * *$} & \multirow{3}{*}{$\mathrm{I}(1$} \\
\hline & & $5 \%$ & -3.536601 & & & & $5 \%$ & -3.533083 & & \\
\hline & & \multicolumn{2}{|c|}{$10 \%-3.200320$} & & & & \multicolumn{2}{|c|}{$10 \%-3.198312$} & & \\
\hline & & $1 \%$ & -4.211868 & \multirow{3}{*}{0.7096} & \multirow{3}{*}{ NS } & \multirow{3}{*}{-3.529758} & $1 \%$ & -4.211868 & \multirow{3}{*}{$0.0500^{* * *}$} & \multirow{3}{*}{$\mathrm{I}(1)$} \\
\hline \multirow[t]{3}{*}{$L n \mathrm{OAD}$} & -1.749397 & $5 \%$ & -3.529758 & & & & $5 \%$ & -3.525355 & & \\
\hline & & $10 \%$ & -3.196411 & & & & $10 \%$ & -3.196411 & & \\
\hline & & $1 \%$ & -4.175640 & \multirow{3}{*}{0.5544} & \multirow{3}{*}{ NS } & \multirow{3}{*}{-6.789065} & $1 \%$ & -4.180911 & \multirow{3}{*}{$0.0000 * * *$} & \multirow{3}{*}{$\mathrm{I}(1$} \\
\hline \multirow[t]{3}{*}{ LnTSE } & -3.515523 & $5 \%$ & -3.513075 & & & & $5 \%$ & -3.515523 & & \\
\hline & & $10 \%$ & -3.186854 & & & & $10 \%$ & -3.188259 & & \\
\hline & & $1 \%$ & -4.175640 & \multirow{3}{*}{0.7473} & \multirow{3}{*}{ NS } & \multirow{3}{*}{-4.507898} & $1 \%$ & -4.211868 & \multirow{3}{*}{$0.0047^{* * *}$} & \multirow{3}{*}{$\mathrm{I}(1)$} \\
\hline \multirow[t]{2}{*}{$L n$ LEAB } & -1.671836 & $5 \%$ & -3.513075 & & & & $5 \%$ & -3.529758 & & \\
\hline & & $10 \%$ & -3.186854 & & & & $10 \%$ & -3.196411 & & \\
\hline
\end{tabular}

Source: Author's computation using E-view 9 (2017)

$* * *$ depicts that the variable is stationary at $5 \%$

NS depicts Non-Stationary

Table 2. Result for the Philips-Peron (PP) Unit Root Test

\begin{tabular}{|c|c|c|c|c|c|c|c|c|c|}
\hline \multicolumn{10}{|c|}{ Philips-Peron (PP) test with intercept only } \\
\hline \multirow[t]{2}{*}{ Variables } & \multicolumn{4}{|c|}{ Level } & \multicolumn{5}{|c|}{$1^{\text {st }}$ Difference } \\
\hline & Test Statistic & Critical values & P-value & Remarks & $\begin{array}{c}\text { Test Statistic } \\
\left(1^{\text {st }} \text { Diff }\right)\end{array}$ & Criti & ical values & P-value & Remarks \\
\hline \multirow{3}{*}{$\delta \ln R G D P$} & \multirow{3}{*}{-5.865153} & $1 \% \quad-3.584743$ & \multirow{3}{*}{$0.0000^{* * *}$} & \multirow{3}{*}{$\mathrm{I}(0)$} & \multirow{3}{*}{---} & & --- & \multirow{3}{*}{---} & \multirow{3}{*}{---} \\
\hline & & $5 \% \quad-2.928142$ & & & & & --- & & \\
\hline & & $10 \% \quad-2.602225$ & & & & & --- & & \\
\hline \multirow[t]{2}{*}{$\operatorname{LnPCI}$} & \multirow[t]{2}{*}{-0.523896} & $5 \% \quad-2.928142$ & \multirow[t]{2}{*}{0.8768} & \multirow[t]{2}{*}{ NS } & \multirow[t]{2}{*}{-5.807749} & $5 \%$ & -2.929734 & \multirow[t]{2}{*}{$0.0000^{* * *}$} & \multirow[t]{2}{*}{$\mathrm{I}(1)$} \\
\hline & & $10 \% \quad-2.602225$ & & & & $10 \%$ & -2.603064 & & \\
\hline \multirow{3}{*}{ LnWAS } & \multirow{3}{*}{1.606509} & $1 \% \quad-3.584743$ & \multirow{3}{*}{0.9993} & \multirow{3}{*}{ NS } & \multirow{3}{*}{-3.223807} & $1 \%$ & -3.588509 & \multirow{3}{*}{$0.0000^{* * *}$} & \multirow{3}{*}{$\mathrm{I}(1)$} \\
\hline & & $5 \% \quad-2.928142$ & & & & & -2.929734 & & \\
\hline & & $10 \% \quad-2.602225$ & & & & $10 \%$ & -2.603064 & & \\
\hline $\operatorname{LnOAD}$ & -0.302097 & $5 \% \quad-2.928142$ & 0.9164 & NS & -4.301057 & $5 \%$ & -2.929734 & $0.0014 * * *$ & $\mathrm{I}(1)$ \\
\hline & & $10 \% \quad-2.602225$ & & & & $10 \%$ & -2.603064 & & \\
\hline & & $1 \% \quad-3.584743$ & & & & $1 \%$ & -3.588509 & & \\
\hline LnTSE & -2.928142 & $5 \%-3.304396$ & 0.2005 & NS & -6.133095 & $5 \%$ & -2.929734 & $0.0000^{* * *}$ & $\mathrm{I}(1)$ \\
\hline & & $10 \% \quad-2.602225$ & & & & $10 \%$ & -2.603064 & & \\
\hline & & -2.622585 & & & & & -2.622585 & & \\
\hline $\operatorname{LnLEAB}$ & -1.191932 & -1.949097 & 0.2096 & NS & -2.136541 & $5 \%$ & -1.949097 & $0.0329 * * *$ & $\mathrm{I}(1)$ \\
\hline & & -1.611824 & & & & $10 \%$ & -1.611824 & & \\
\hline & & Philip & Peron (PP) $t$ & with tre & and intercept & & & & \\
\hline & & $1 \%-4.175640$ & & & & & --- & & \\
\hline & & $10 \% \quad-3.188259$ & & & & $10 \%$ & -3.189732 & & \\
\hline
\end{tabular}




\begin{tabular}{|c|c|c|c|c|c|c|c|c|c|c|}
\hline \multirow{3}{*}{ LnYAD } & \multirow{3}{*}{-2.043955} & $1 \%$ & -4.180911 & \multirow{3}{*}{0.5616} & \multirow{3}{*}{ NS } & \multirow{3}{*}{-7.105871} & $1 \%$ & -4.186481 & \multirow{3}{*}{$0.0000^{* * *}$} & \multirow{3}{*}{$\mathrm{I}(1$} \\
\hline & & $5 \%$ & -3.515523 & & & & $5 \%$ & -3.518090 & & \\
\hline & & $10 \%$ & -3.188259 & & & & \multicolumn{2}{|c|}{$10 \%-3.189732$} & & \\
\hline \multirow{3}{*}{$\operatorname{Ln} \mathrm{OAD}$} & \multirow{3}{*}{-1.118578} & $1 \%$ & -4.175640 & \multirow{3}{*}{0.9144} & \multirow{3}{*}{ NS } & \multirow{3}{*}{-4.422433} & $1 \%$ & -4.180911 & \multirow{3}{*}{$0.0053^{* * *}$} & \multirow{3}{*}{$\mathrm{I}(1$} \\
\hline & & $5 \%$ & -3.513075 & & & & $5 \%$ & -3.515523 & & \\
\hline & & $10 \%$ & -3.186854 & & & & $10 \%$ & -3.188259 & & \\
\hline \multirow{3}{*}{ LnTSE } & \multirow{3}{*}{-2.034796} & $1 \%$ & -4.175640 & \multirow{3}{*}{0.5669} & \multirow{3}{*}{ NS } & \multirow{3}{*}{-6.797143} & $1 \%$ & -4.180911 & \multirow{3}{*}{$0.0000 * * *$} & \multirow{3}{*}{$\mathrm{I}(1)$} \\
\hline & & $5 \%$ & -3.513075 & & & & $5 \%$ & -3.515523 & & \\
\hline & & $10 \%$ & -3.186854 & & & & $10 \%$ & -3.188259 & & \\
\hline \multirow{3}{*}{$\operatorname{LnLEAB}$} & \multirow{3}{*}{1.901062} & $1 \%$ & -3.610453 & \multirow{3}{*}{0.9997} & \multirow{3}{*}{ NS } & \multirow{3}{*}{-3.804038} & $1 \%$ & -3.610453 & \multirow{3}{*}{$0.0060^{* * *}$} & \multirow{3}{*}{$\mathrm{I}(1)$} \\
\hline & & $5 \%$ & -2.938987 & & & & $5 \%$ & -2.938987 & & \\
\hline & & $10 \%$ & -2.607932 & & & & $10 \%$ & -2.607932 & & \\
\hline
\end{tabular}

Source: Author's computation using E-view 9 (2017)

$* * *$ depicts that the variable is stationary at $5 \%$

NS depicts Non-Stationary

\subsection{Lag Length Selection Criteria Results}

After investigating the order of integration the study proceeded to the determination of optimal lag length incorporated for each variable in the ARDL and VAR models. This is important because under parameterization would result in a biased result and correspondingly, over-parameterization lessens the power of the tests. As argued in Braun and Mittnik (1993), IRF and FEDC derived from the estimated VAR are inconsistent once the lag length varies from the true length. Moreover, Lutkepohl (1993) suggests that while over fitting causes an upsurge in the mean-square forecast errors of the VAR; nevertheless under fitting generates autocorrelated errors which results in inconsistent estimate. To choose the appropriate lag length, therefore, following the literature the information criteria such as the Hannan- Quinn information criteria (HQ), the Akaike information criteria (AIC), the Schwarz information criteria (SIC), the Log Likelihood (LL) and the Final Prediction Error (FPE) were considered. The results are presented in table 3. As depicted in the table the optimal lag order chosen for ARDL model (19) and VAR model (20) is three (3).

Table 3. VAR lag order selection criteria

\begin{tabular}{lccccc}
\hline Lag & LR & \multicolumn{1}{l}{ FPE } & AIC & \multicolumn{1}{l}{ SC } & HQ \\
\hline 0 & NA & $1.94 \mathrm{e}-14$ & -11.70628 & -11.41957 & -11.60055 \\
1 & 1117.649 & $2.65 \mathrm{e}-27$ & -41.36003 & -39.06638 & -40.51420 \\
2 & 202.1916 & $2.27 \mathrm{e}-29$ & -46.30209 & -42.00148 & -44.71616 \\
3 & $128.0812^{*}$ & $8.49 \mathrm{e}-31^{*}$ & $-50.12212^{*}$ & $-43.81457^{*}$ & $-47.79609^{*}$ \\
\hline
\end{tabular}

* indicates lag order selected by the criterion

LR: sequential modified LR test statistic (each test at 5\% level)

FPE: Final prediction error

AIC: Akaike information criterion

SC: Schwarz information criterion

HQ: Hannan-Quinn information criterion

\subsection{Bounds Testing Approach to Cointegration}

Having determined the stationarity of each time series and the appropriate lag-length, "Bounds Test" of cointegration was performed to verify the (joint) significance of the coefficients of equation (19) earlier specified. This is done by imposing zero restrictions on the estimated long-run coefficients of the growth rate of per capita real GDP, income per capita, working age share, youth age dependency, adult age dependency, human capital accumulation and life expectancy at birth. The results of the bounds test are reported in table 4 . As can be seen from the table, the computed F-statistic (7.398593) is greater than upper bond value of (3.61) at five per cent 
level of significance. Thus, the null hypotheses of no cointegrating relationship among the variables is rejected. Thus, the possibility of the estimated relationship being spurious is ruled out.

Table 4. Results of bound test approach to cointegration (Wald test)

\begin{tabular}{cccc}
\hline Level of Significance & \multicolumn{2}{c}{ Critical value } & F-calculated / Computed \\
\cline { 2 - 3 }$(\alpha \%)$ & Lower bound I(0) & Upper bound I(1) & F-statistic \\
\hline 10 & 2.12 & 3.23 & \\
$\mathbf{5}$ & 2.45 & 3.61 & $\mathbf{7 . 3 9 8 5 9 3}$ \\
2.5 & 2.75 & 3.99 & \\
1 & 3.15 & 4.43 & \\
\hline
\end{tabular}

Source: Author's computation using E-view 9 (2017)

\subsection{Innovation Accounting Technique}

In this section, in order to provide an intuitive insight, the study generated IRF functions which allowed us to trace responses of a variable to its own shocks and shocks in other variables. In this instance in particular, from the IRFs we assessed the direction, magnitude and persistent of economic growth responses to innovations in income per capita, working age share, youth age dependency, adult age dependency, human capital accumulation and life expectancy at birth over ten years to enable us capture both the short term and long term responses using the Cholesky decomposition. The IRF analysis results are presented in figure 3. Also, in order to further strengthen the robustness of the analysis FEVD for one-year to ten-year forecast periods was, in addition, applied. Explicitly, this procedure is used to approximate the contribution of each variable to the variability of the whole system beyond the sample period. The FEDC analysis results are presented in table 5.

Table 5. Variance decomposition of growth rate of per capita real GDP (RGDPPCGR)

\begin{tabular}{lllllllll}
\hline Period & S.E. & RGDPPCGR & LNRGDPPC & LNWAS & LNYAD & LNOAD & LNTSE & LNLEAB \\
\hline 1 & 5.034678 & 100.0000 & 0.000000 & 0.000000 & 0.000000 & 0.000000 & 0.000000 & 0.000000 \\
2 & 6.520267 & 96.40098 & 0.348022 & 2.954079 & 0.196126 & 0.018151 & 0.000229 & 0.082412 \\
3 & 6.904253 & 91.68307 & 3.590633 & 3.323395 & 1.068572 & 0.150716 & 0.109978 & 0.073637 \\
4 & 8.11726 & 67.76017 & 2.600444 & 13.39401 & 5.467711 & 2.071474 & 8.337244 & 0.368944 \\
5 & 16.36178 & 88.47107 & 1.982254 & 3.955319 & 1.749381 & 0.542849 & 3.040417 & 0.258714 \\
6 & 22.85843 & 90.16950 & 1.292954 & 4.241029 & 0.902031 & 0.379043 & 1.557916 & 1.457523 \\
7 & 23.5346 & 85.24254 & 4.576269 & 4.661844 & 1.376422 & 0.464938 & 1.469823 & 2.208163 \\
8 & 28.32521 & 78.33001 & 3.397945 & 5.06001 & 5.935398 & 0.646546 & 5.105426 & 1.524668 \\
9 & 42.20945 & 80.02113 & 3.098285 & 6.587756 & 3.103462 & 1.146359 & 5.34945 & 0.693564 \\
10 & 80.47963 & 92.71327 & 0.986172 & 2.674799 & 0.919235 & 0.480545 & 1.476311 & 0.749667 \\
\hline
\end{tabular}

Cholesky Ordering: RGDPPCGR LNRGDPPC LNWAS LNYAD LNOAD LNTSE LNLEAB

Source: Author's computation using E-view 9 (2017) 
Response to Cholesky One S.D. Innovations \pm 2 S.E.

Response of RGDPPCGR to LNWAS

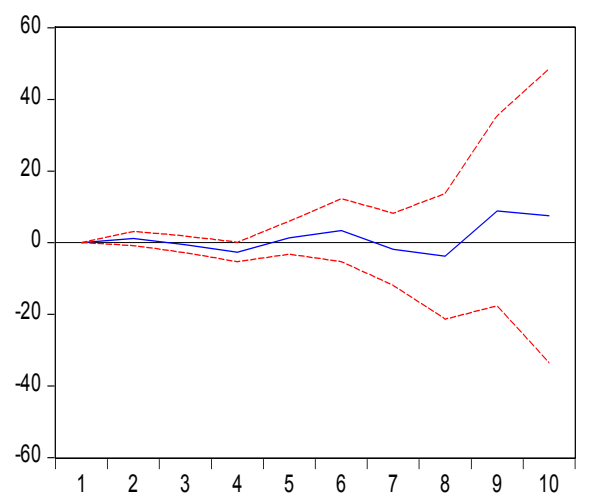

Response of RGDPPCGR to LNOAD

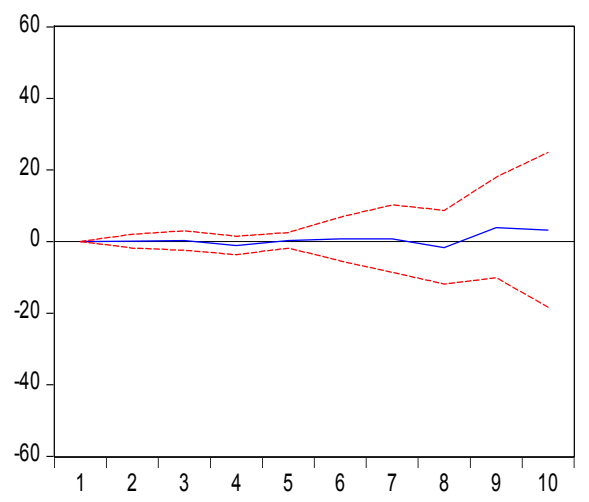

Response of RGDPPCGR to LNYAD

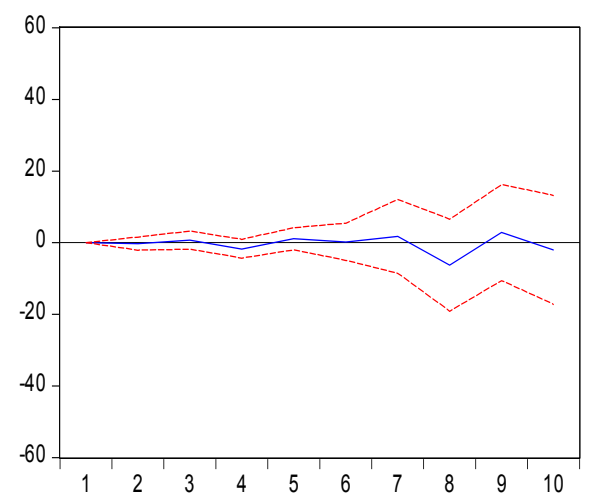

Response of RGDPPCGR to LNLEAB

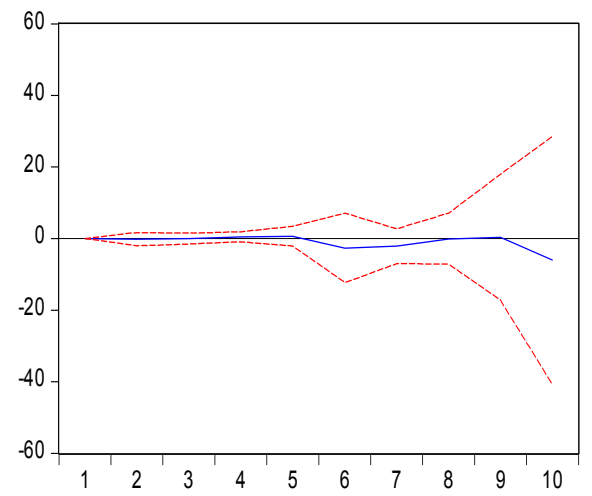

Figure 3. Impulse response analysis of economic growth

Source: Author's computation using E-view 9 (2017)

\subsubsection{Impulse Response Analysis of Economic Growth}

As can be seen from the figure 3, the first horizontal segment of the figure revealed the response of economic growth to both working age share and youth age dependency, while the second horizontal segment bared the response of economic growth to both adult age dependency and life expectancy at birth shocks. As for the response of economic growth to a shock in working age share it was observed that although a shock in working age share did not have any effect on economic growth in the first year, afterwards, it became positive in the second year reaching 1.12 percent but thereafter assumed negative values from year three through to year four. However, this negative effect was reversed from the fifth year as shock in working age share resulted in 3.4 percent increase in economic growth before it dipped further in the seventh and eight years by 1.9 and 3.8 percent respectively but starts rising afterwards and maintained a positive response all through the periods. The implication of the above finding thus suggests that, although, labour force is a key factor for a viable rate of economic expansion as well as the engine of economic growth and development for labour intensive economies like Nigeria, however, having a well-educated, healthier, and larger labour force will only benefit the economy only if the additional workers can find jobs.

Additionally, as can be observed from the figure, our results showed that the estimated impacts of the change in youth age dependency and change in adult age dependency on economic growth are distinct. On the one hand, the response of growth to youth age dependency in response to a one standard innovation shock to youth age dependency did not produce any effect in the first year. Between the second and the fifth year, the response of growth was oscillatory implying that there is no definite pattern of response of economic growth to youth age dependency. After the sixth period, a similar pattern of fluctuations was also displayed till the tenth year period. On the other hand, the response of economic growth to shock occasioned by adult age dependency revealed a similar pattern in the first period as a one standard deviation disturbance originating from adult age dependency 
did not have an immediate impact. It became positive from the second year to about the third year period before it plummeted in the fourth year. However, this negative effect was reversed from the fifth year as shock in adult age dependency resulted in 0.29 percent increase in economic growth and thereafter, with the exception of eight year period whereby it became negative, continue to increase till the tenth year period. These results suggest that, while, an enormous size of the population of the elderly and the children relative to working age population impedes economic growth as both constitute a demographic burden; however, an increasing relative size of the elderly to total population has a lesser negative impact on economic growth than an increasing relative size of the population of children. An implication of this finding is that even though Nigeria is expected to begin to face ageing society by 2030 , the economic growth can be boosted by investing more on human capital of the rapidly growing population of young people, considered to be an omen of prosperity, who need to be provided with proper education, training and balanced health facilities in order to become assets for the country.

Finally, from the figure, in response to a one standard deviation shock to life expectancy at birth, it was observed that economic growth did not produce any effect in the first year. Thereafter, with the exception of fourth, fifth and ninth year periods whereby it was approaching zero, economic growth maintained a negative response to shock to life expectancy at birth all through the periods. An insight from this finding implies that increased life expectancy occasioned by the innovations in the field of health accelerate the growth of the population, in particular, the proportion of elderly. As such, may affect economic growth mainly through three mechanisms: public social expenditure via pension and health care expenditures; low savings and consumption patterns through a high dependency from the population of the elderly; and tax burden as comparatively lesser working-age cohorts will be saddled by the need to pay for the support of, and care for, a greater share of the population of the elderly. This finding, thus, lend credence to the pessimistic view which reasoned that the inequality in a country's population age structure, particularly, a greater proportion of the population of the elderly, depresses the country's productivity level; and corroborates the empirical findings of Navaneetham and Dharmalingam (2012) for South Asia, Albuquerque (2015) for the case of Portugal, Ismail, Rahman, and Hamid (2015) for the case of Malaysia.

\subsubsection{Forecast Error Variance Decomposition of Economic Growth}

An examination of the FEVD per capita RGDP growth rate in table 5 in the appendix II showed that the lion's share of the variation experienced by per capita RGDP growth rate was attributed to its own shock. The magnitude was 100 percent in the first period and fell to 92.71 percent at the end of the 10 year period horizon. The contribution and influence of the other 6 variables was quite marginal. The highest was by working age share, which contributed 13.39 percent in the fourth period and afterwards marginally declined to 2.64 percent in the tenth period. Life expectancy and change in adult age dependency had the least contribution among the endogenous variables. This result further reinforced the findings obtained from the IRFs analysis in the preceding section. In sum, both the IRF and FEVD lend credence to the pessimistic view which maintained that the inequality in a country's population age structure, particularly, a greater share of the population of the elderly defined as persons aged 60 years and above, dampens the country's productivity level.

\subsubsection{Post-Estimation Diagnostics Tests}

Having estimated the VAR model (20) appropriate diagnostic tests were also performed in order to examine robustness of the VAR models. To start with, in order to test the stability conditions of the model, the graphical root characteristic polynomial was employed. The outcomes of this method, as depicted in figure 4, showed that all the roots of the characteristic polynomial for the model were in the unit circle suggesting that the defined VAR model was stable. This finding showed that the VAR model satisfy the stability conditions. Afterwards, VAR residual serial correlation Lagrangian Multiplier (LM) test to check serial correlation problem. This was followed by Jarque-Bera (JB) test to check normality. Lastly, in order to observe the variance constancy of the residuals, White's heteroskedasticity test with no cross terms was applied. The findings revealed that the model specifications employed in the VARs estimation were appropriate. While the diagnostic test results are not presented here to save space, nonetheless, they are available upon request. 


\section{Inverse Roots of AR Characteristic Polynomial}

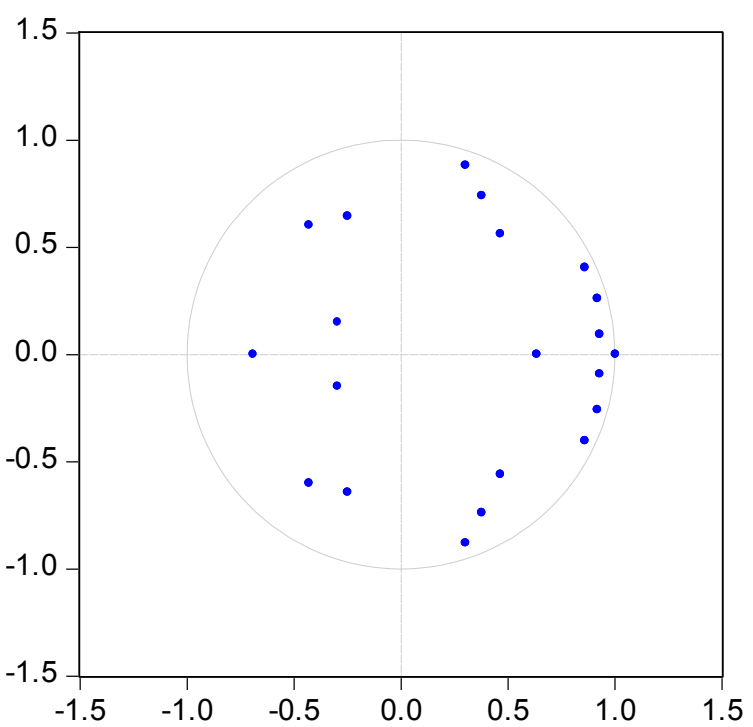

Figure 4. Inverse roots of AR characteristic polynomial of VAR model

Source: Author's computation using E-view 9 (2017)

\section{Conclusion and Policy Recommendation}

This paper empirically investigated the economic growth consequences of population ageing in Nigeria spanning between the period 1970 and 2015. Innovation Accounting Techniques was applied to assess the dynamic interactions among the variables. The findings obtained revealed that the innovation in life expectancy and change in adult age dependency had the least contribution to the variation in per capita real GDP growth rate. The magnitude ranges between 1.45 and 8.33 percent. These results, thus, lend credence to the pessimistic view which contend that the inequality in a country's population age structure, particularly, a greater share of the population of the elderly defined as persons aged 60 years and above, dampens the country's productivity level. Thus, premised on this finding, apposite policies that will offset the imminent demographic pressure, enhance and quicken economic growth in the country should be pursued. First of all, any long term growth strategy aimed at boosting per capita income at a sustainable rate over the next ten (10) to fifteen (15) years needs to envision policies and reforms that are likely to foster savings and boost returns on them. As elsewhere, in Nigeria, given the substantial increase in average life spans during the past thirty (30) years, raising the retirement age in order to extend the period when households are most prone to save would be reasonable. As stated earlier, the increase in longevity will not only bring about an upsurge in savings as well as the savings time span, but also provide more resources for investment. Another useful step would be to encourage younger Nigerian to save more. In addition, an insight from the analysis showed that, albeit, Nigeria is expected to begin to face ageing society by 2030, nonetheless, the economic growth can still be boosted by investing more on human capital of the rapidly growing population of young people, considered to be an omen of prosperity, who need to be provided with proper education, training and balanced health facilities in order to become assets for the country.

\section{References}

Acemoglu, D., \& Restrepo, P. (2017). Secular Stagnation? The Effect of Aging on Economic Growth in the Age of Automation (No. w23077). National Bureau of Economic Research. https://doi.org/10.3386/w23077

Aghion, P., \& Howitt, P. (1990). A model of growth through creative destruction (No. w3223). National Bureau of Economic Research. https://doi.org/10.3386/w3223

Aigner-Walder, B., \& Döring, T. (2012). The effects of population ageing on private consumption - A simulation for Austria based on household data up to 2050. Eurasian Economic Review, 2(1), 63-80.

Aisa, R., \& Pueyo, F. (2013). Population aging, health care, and growth: a comment on the effects of capital $\begin{array}{lllll}\text { accumulation. Journal of Population Economics, 26(4), 1285-1301. } & \text {. }\end{array}$ https://doi.org/10.1007/s00148-012-0448-2

Ajomale, O. (2007). Country report: ageing in Nigeria-current state, social and economic implications. African 
Gerontological Society.

Albuquerque, P. C. (2015). Demographics and the Portuguese economic growth.

Alders, P., \& Broer, D. P. (2005). Ageing, fertility, and growth. Journal of Public Economics, 89(5), 1075-1095. https://doi.org/10.1016/j.jpubeco.2004.06.001

Asagba, A. (2005). Research and the formulation and implementation of ageing policy in Africa: the case of Nigeria. Generations Review, 15(2), 39-41.

Athukorala, P. C., \& Tsai, P. L. (2003). Determinants of household saving in Taiwan: growth, demography and public policy. The Journal of Development Studies, 39(5), 65-88. https://doi.org/10.1080/00220380412331333149

Bairoliya, N., Miller, R., \& Saxena, A. (2017). The Macroeconomic Impact of Fertility Changes in an Aging Population.

Barro, R. J. (1991). Economic growth in a cross section of countries. The quarterly journal of economics, 106(2), 407-443. https://doi.org/10.2307/2937943

Barro, R. J., \& Lee, J. W. (1994, June). Sources of economic growth. In Carnegie-Rochester conference series on public policy (Vol. 40, pp. 1-46). North-Holland. https://doi.org/10.2307/2937943

Barro, R. J., \& Sala-i-Martin, X. (1995). Technological diffusion, convergence, and growth (No. w5151). National Bureau of Economic Research. https://doi.org/10.3386/w5151

Bloom, D. E., \& Williamson, J. G. (1998). Demographic transitions and economic miracles in emerging Asia. The World Bank Economic Review, 12(3), 419-455. https://doi.org/10.1093/wber/12.3.419

Bloom, D. E., Canning, D., \& Fink, G. (2010). Implications of population ageing for economic growth. Oxford review of economic policy, 26(4), 583-612. https://doi.org/10.1093/oxrep/grq038

Bloom, D. E., Canning, D., \& Malaney, P. N. (1999). Demographic change and economic growth in Asia. CID.

Bloom, D. E., Canning, D., \& Malaney, P. N. (2000). Population dynamics and economic growth in Asia. Population and Development Review, 26, 257-290.

Bloom, D. E., Canning, D., Fink, G., \& Finlay, J. E. (2010). The cost of low fertility in Europe. European Journal of Population/Revue Européenne de Démographie, 26(2), 141-158. https://doi.org/10.1007/s10680-009-9182-1

Braun, P. A., \& Mittnik, S. (1993). Misspecifications in vector autoregressions and their effects on impulse responses and variance decompositions. Journal of Econometrics, 59(3), 319-341. https://doi.org/10.1016/0304-4076(93)90029-5

Cass, D. (1965). Optimum growth in an aggregative model of capital accumulation. The Review of economic studies, 32(3), 233-240. https://doi.org/10.2307/2295827

Cervellati, M., \& Sunde, U. (2010). Longevity and lifetime labor supply: Evidence and implications revisited. Report, University of Bologna.

Cervellati, M., \& Sunde, U. (2011). Life expectancy and economic growth: the role of the demographic transition. Journal of economic growth, 16(2), 99-133. https://doi.org/10.1007/s10887-011-9065-2

Davies, R. B., \& Reed, R. R. (2006). Population aging, foreign direct investment, and tax competition.

Desa, U. (2017). United Nations Department of Economic and Social Affairs.

Dolado, J. J., \& Lütkepohl, H. (1996). Making Wald tests work for cointegrated VAR systems. Econometric Reviews, 15(4), 369-386. https://doi.org/10.1080/07474939608800362

El Mekkaoui-De Freitas, N., \& Martins, J. O. (2014). Health, Pension Benefits and Longevity How They Affect Household Savings? The Journal of the Economics of Ageing, 3, 21-28. https://doi.org/10.1016/j.jeoa.2014.03.001

Enders, W. (2008). Applied econometric time series. John Wiley \& Sons.

Finch, N. (2014). Why are women more likely than men to extend paid work? The impact of work-family life history. European Journal of Ageing, 11(1), 31-39. https://doi.org/10.1007/s10433-013-0290-8

Fougère, M., Harvey, S., Mercenier, J., \& Mérette, M. (2009). Population ageing, time allocation and human capital: A general equilibrium analysis for Canada. Economic Modelling, 26(1), 30-39. https://doi.org/10.1016/j.econmod.2008.05.007 
Fürnkranz-Prskawetz, A., Lee, R. D., Lee, S. H., Mason, A., Miller, T., Mwabu, G., \& Soyibo, A. (2013). Population change and economic growth in Africa.

Gomez, R., \& De Cos, P. H. (2008). Does population ageing promote faster economic growth? Review of Income and Wealth, 54(3), 350-372. https://doi.org/10.1111/j.1475-4991.2008.00279.x

Gonzalez-Eiras, M., \& Niepelt, D. (2012). Ageing, government budgets, retirement, and growth. European Economic Review, 56(1), 97-115. https://doi.org/10.1016/j.euroecorev.2011.05.007

Harris, R., \& Sollis, R. (2003). Applied time series modelling and forecasting. Wiley.

Hashimoto, K. I., \& Tabata, K. (2010). Population aging, health care, and growth. Journal of Population Economics, 23(2), 571-593. https://doi.org/10.1007/s00148-008-0216-5

Hock, H., \& Weil, D. N. (2012). On the dynamics of the age structure, dependency, and consumption. Journal of population economics, 25(3), 1019-1043. https://doi.org/10.1007/s00148-011-0372-x

Hundie, S. K. (2014). Savings, investment and economic growth in Ethiopia: Evidence from ARDL approach to co-integration and TYDL Granger-causality tests. Journal of Economics and International Finance, 6(10), 232. https://doi.org/10.5897/JEIF2014.0600

Inder, B. (1993). Estimating long-run relationships in economics: A comparison of different approaches. Journal of econometrics, 57(1-3), 53-68. https://doi.org/10.1016/0304-4076(93)90058-D

Ismail, N. W., Rahman, H. S. W. A., \& Hamid, T. (2015). Does population aging affect economic growth in Malaysia. Prosiding Perkem, 10, 205-210.

Joubert, J., \& Bradshawb, D. (2006). Population Ageing and Health Challenges.

Koopmans, T. C. (1965). On the concept of optimal economic growth.

Lee, R. D. (2014). Macroeconomic consequences of population aging in the United States: Overview of a national academy report. The American Economic Review, 104(5), 234-239. https://doi.org/10.1257/aer.104.5.234

Lee, R., \& Mason, A. (2014). Is low fertility really a problem? Population aging, dependency, and consumption. Science, 346(6206), 229-234. https://doi.org/10.1126/science.1250542

Lee, S. H., Mason, A., \& Park, D. (2011). Why does population aging matter so much for Asia? Population aging, economic security and economic growth in Asia. ERIA Discussion Paper Series, 4, 1-34. https://doi.org/10.2139/ssrn.1960877

Lisenkova, K., \& Mérette, M. R. W. (2012). The Impact of Population Ageing on the Labour Market: Evidence from Overlapping Generations Computable General Equilibrium (OLG-CGE) Model of Scotland. Discussion paper in Economic, Strathclyde, 12-13.

Loumrhari, G. (2014). Ageing, longevity and savings: The case of Morocco. International Journal of Economics and Financial Issues, 4(2), 344.

Lucas, R. E. (1990). Why doesn't capital flow from rich to poor countries? The American Economic Review, 80(2), 92-96.

Lütkepohl, H. (1993). Introduction to multiple time series. Springer Verlag, 9(4), 500-503.

Maestas, N., Mullen, K. J., \& Powell, D. (2016). The effect of population aging on economic growth, the labour force and productivity (No. w22452). National Bureau of Economic Research. https://doi.org/10.3386/w22452

Mankiw, N. G., Romer, D., \& Weil, D. N. (1992). A contribution to the empirics of economic growth. The quarterly journal of economics, 107(2), 407-437. https://doi.org/10.2307/2118477

Mason, A. (2005). Demographic transition and demographic dividends in developed and developing countries. In United Nations expert group meeting on social and economic implications of changing population age structures (Vol. 31).

Nagarajan, N. R., Teixeira, A. A., \& Silva, S. T. (2016). The impact of an ageing population on economic growth: an exploratory review of the main mechanisms. Análise Social, 4-35.

Narciso, A. (2010). The impact of population ageing on international capital flows.

National Population Commission. (2017). National population census. Abuja, Nigeria: National Population Commission. 
Nations, U. (2017). World population prospects, the 2017 revision. Document de Travail.

Navaneetham, K., \& Dharmalingam, A. (2012). A review of age structural transition and demographic dividend in South Asia: Opportunities and challenges. Journal of Population Ageing, 5(4), 281-298. https://doi.org/10.1007/s12062-012-9071-y

Ono, T. (2003). Social security policy with public debt in an aging economy. Journal of Population Economics, 16(2), 363-387. https://doi.org/10.1007/s001480300148

Park, D., \& Shin, K. (2012). Impact of population aging on Asia's future growth. Aging, Economic Growth, and Old-Age Security in Asia, 83. https://doi.org/10.4337/9781781953600.00009

Pesaran, M. H., \& Pesaran, B. (1997). Working with Microfit 4.0: interactive econometric analysis; [Windows version]. Oxford University Press.

Pesaran, M. H., Shin, Y., \& Smith, R. J. (2001). Bounds testing approaches to the analysis of level relationships. Journal of applied econometrics, 16(3), 289-326. https://doi.org/10.1002/jae.616

Population Division. (2016). World Population Prospects: The 2017 Revision.

Prettner, K. (2013). Population aging and endogenous economic growth. Journal of population economics, 26(2), 811-834. https://doi.org/10.1007/s00148-012-0441-9

Romer, D. (1993). Openness and inflation: theory and evidence. The Quarterly Journal of Economics, 108(4), 869-903. https://doi.org/10.2307/2118453

Sachs, J. D., Warner, A., Åslund, A., \& Fischer, S. (1995). Economic reform and the process of global integration. Brookings papers on economic activity, 1995(1), 1-118. https://doi.org/10.2307/2534573

Sankay, O. J., Ismail, R., \& Shaari, H. (2010). The impact of human capital development on the economic growth of Nigeria. Prosiding Perkem, 5(1), 63-72.

Shan, J. (2005). Does financial development 'lead' economic growth? A vector auto-regression appraisal. Applied Economics, 37(12), 1353-1367. https://doi.org/10.1080/00036840500118762

Sharpe, A. (2011). Is Ageing a Drag on Productivity Growth? A Review Article on Ageing, Health and Productivity: The Economics of Increased Life Expectancy. International Productivity Monitor, (21).

Sims, C. A. (1980). Macroeconomics and reality. Econometrica: Journal of the Econometric Society, 1-48. https://doi.org/10.2307/1912017

Sukpaiboonwat, S., Plyngam, S., \& Jaroensathapornkul, J. (2014). Does an Ageing Population Diminish or Enhance Economic Growth?: A Survey of Literature.

Toda, H. Y., \& Phillips, P. C. (1993). Vector autoregressions and causality. Econometrica: Journal of the Econometric Society, 1367-1393. https://doi.org/10.2307/2951647

Toda, H. Y., \& Phillips, P. C. (1994). Vector autoregression and causality: a theoretical overview and simulation study. Econometric reviews, 13(2), 259-285. https://doi.org/10.1080/07474939408800286

Toda, H. Y., \& Yamamoto, T. (1995). Statistical inference in vector autoregressions with possibly integrated processes. Journal of econometrics, 66(1), 225-250. https://doi.org/10.1016/0304-4076(94)01616-8

Velarde, M., \& Herrmann, R. (2014). The Journal of the Economics of Ageing.

Wei, T., Zhu, Q., \& Glomsrod, S. (2018). Ageing Impact on the Economy and Emissions in China: A Global Computable General Equilibrium Analysis. Energies, 11(4), 817. https://doi.org/10.3390/en11040817

World Health Organization. (2015). Health Worker Role in Providing Safe Abortion Care and Post Abortion Contraception. World Health Organization.

Yamada, H., \& Toda, H. Y. (1998). Inference in possibly integrated vector autoregressive models: Some finite sample evidence. Journal of Econometrics, 86(1), 55-95. https://doi.org/10.1016/S0304-4076(97)00109-7

Zhang, J., Zhang, J., \& Lee, R. (2003). Rising longevity, education, savings, and growth. Journal of Development Economics, 70(1), 83-101. https://doi.org/10.1016/S0304-3878(02)00088-3

\section{Copyrights}

Copyright for this article is retained by the author(s), with first publication rights granted to the journal.

This is an open-access article distributed under the terms and conditions of the Creative Commons Attribution license (http://creativecommons.org/licenses/by/4.0/). 